\title{
THE PROCESS OF CONCEPTUALIZATION IN SOLVING GEOMETRIC-FUNCTION PROBLEMS
}

\author{
Masta Hutajulu1 ${ }^{1}$, Krisna Satrio Perbowo ${ }^{2}$, Fiki Alghadari ${ }^{3}$, Eva Dwi Minarti ${ }^{1}$, Wahyu Hidayat ${ }^{{ }^{*}}$ \\ ${ }^{1}$ Institut Keguruan dan Ilmu Pendidikan Siliwangi, Indonesia \\ ${ }^{2}$ University of Warwick, England, UK \\ ${ }^{3}$ STKIP Kusumanegara, Indonesia
}

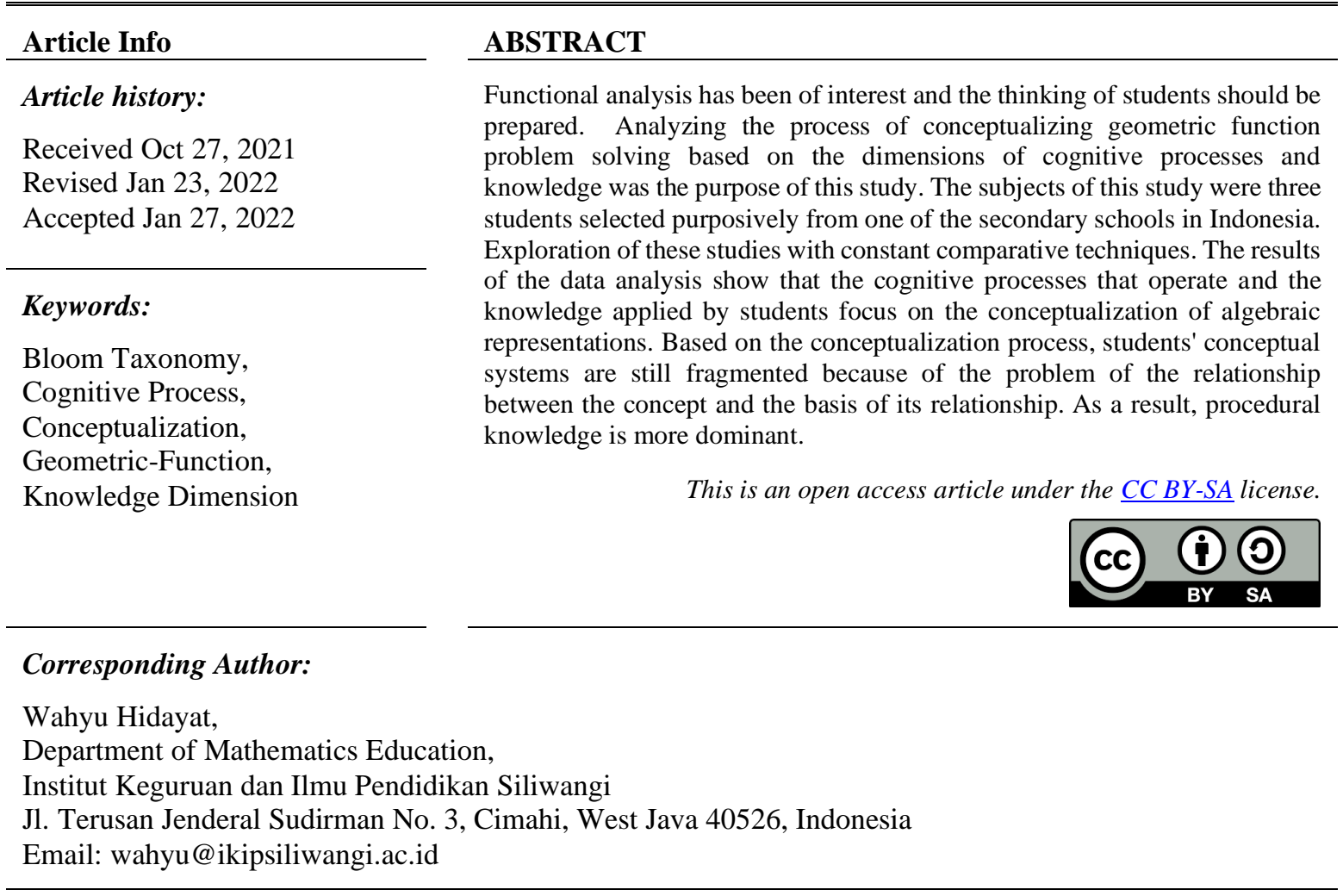

How to Cite:

Hutajulu, M., Perbowo, K. S., Alghadari, F., Minarti, E. D., \& Hidayat, W. (2022). The process of conceptualization in solving geometric-function problems. Infinity, 11(1), 145-162.

\section{INTRODUCTION}

In general mathematics education research, problems have often been involved in the construction or reconstruction of concept schemes, also sometimes intended to be meaningful learning experiences for students (Mumu et al., 2017). For example, one approach that involves problems is problem-based learning (Bartholomew \& Strimel, 2018; Widodo et al., 2019), and besides, there are several other approaches, such as in Hendriana and Fadhillah (2019) which also uses the function of mathematical problems to solve problems. one of them is through a constructivist approach, problems are solved by students, used as learning resources to obtain a new mathematical concept (Hendriana \& Fadhillah, 2019). in this case, solving mathematical problems is required to achieve learning goals. Aside from being a learning resource that aims, the problem that is solved is also subjectively will increase the capacity of each student's ability concerning their mathematical conceptual 
knowledge (Hendriana \& Fadhillah, 2019; Hendriana et al., 2018). For this purpose, the problem is functioned as a conditional source of learning and is said to be so because of the increase in the ability of students on the condition that the solutions they have been able to achieve so that their intellectual capacity increases. However, anything its function, it is subjective for each student that ideally, the solution to the problem is not easy to achieve immediately, and that is the main reason why the problem is not a routine and an intellectual challenge (Alghadari \& Kusuma, 2018; Dossey, 2017; Polya, 1981).

From the information above, for the two modes that function on a problem, the goal is that students can solve by passing conceptual constraints (Dossey, 2017). There will be several cognitive processes that produce a bridging concept to arrive at that goal (Alghadari \& Kusuma, 2018). Hendriana et al. (2018) and Nagle et al. (2013) for instance, said that reasoning is a process of problem-solving. Furthermore, Clancey (2001) says that the conceptualization process occurs in the problem-solving phase. The reasoning is aimed at conceptualizing the solution. On the other hand, Polya (1981) has described cognitive processes and is a productive activity that can be used as a reference to overcome obstacles so that solutions are found. That is the concept of problem-solving steps. We believe that the existence of these steps to help anyone who is confused starts the settlement step. However, what is conceptualized is to complete, and any processes occur for each problem so that a solution appears, it is not a simple sequence (Alghadari et al., 2019; Clancey, 2001; Glaser, 2002).

If until now the problem-solving is considered important, both for learning purposes and improving mathematical abilities, then the conceptualization of problem-solving is part of that assumption. Moreover, the problem solved requires the involvement of various dimensions with several hierarchies of mathematical concepts and different ways of solving that might be applied. This corresponds to the statement of Clancey (2001) that conceptualization includes object and operating differences, and all about the experience, memory, and thought. Because it is already known, there is more than one dimension involved, the reference to problem-solving processes may only be a procedure that is thoroughly seen between procedural and conceptual knowledge. Glaser (2002) states that there is a conceptual theoretical burden when many concepts are gathered in one concept and because the concept of one event is not a careful generation of a pattern so that it becomes very unusual when there is no analysis. Therefore, the occurrence of processes in a particular activity from the problem-solving phase, so that it becomes one goal for further analysis studies that are examined from several dimensional involvement.

\subsection{For Conceptualizing: The Problem and Solving Process}

Regarding a term from a problem, which is related to mathematics, it is said to be a mathematical problem, the existence of a particular procedure is not directly accepted as one of its characteristics, so there are conditions that can derail the definition of a problem. Therefore, it needs to be translated more deeply into the meaning of the procedure, because it concerns the specifications of the problem definition. Rittle-Johnson and Schneider (2015), and Bartholomew and Strimel (2018) suggest that the procedure is not only in the form of algorithms but also actions that may have to be sorted precisely to solve a problem. Concerning the quotation, Alghadari and Kusuma (2018) reveal that procedures can be built by referring to the process when seeking a solution, then the collection of procedures found empirically is generalized as a problem-solving procedure, and it is not a solution to the intended procedure as an algorithm. Furthermore, this is the fact that occurs in historical records concerning the special connection between matter and geometry. So, the procedure referred to and which is not the nature of the problem according to Dossey (2017) and Polya 
(1981) is about the existence of an algorithm. However, for certain cases there are conditions relating to the purpose of the last procedure, which is not an algorithm, and it develops through problem-solving practices (Rittle-Johnson \& Schneider, 2015). Then, at the time of the practice, students are involved in active cognitive processes as well as building meaning (Mumu et al., 2017; Radmehr \& Drake, 2017, 2018). Thus, there is an important meaning of the construction of student knowledge that involves the function of a problem (Alghadari et al., 2019).

This study uses open-ended conceptual problems, as claims, which fulfill the nature and criteria of mathematical problems according to Dossey (2017), which is a problem in the problem itself. Rittle-Johnson and Schneider (2015) have defined conceptual problems as problems that are relatively unfamiliar to students, so they must obtain from their conceptual knowledge compared to procedures they know. These two pieces of literature confirm information about the nature and criteria of the problem. In other words, no algorithm serves to determine completion as a symbolic procedure so that a solution is immediately found (Alghadari \& Kusuma, 2018; Dossey, 2017; Polya, 1981). In the previous section, it was stated that in the phase of problem-solving, there is a series of cognitive processes that are not simple to produce a concept that becomes a bridge to a solution. For the concept in question, it is a process that is not simple and with the hierarchy of mathematical concepts applied, so that it relates to the statement Rittle-Johnson and Schneider (2015), and Wagner and Sharp (2017) that mathematical knowledge requires repeated concepts and layered procedures.

Therefore, solving problems solved by students through conceptualization in which various cognitive processes occur in abstract mathematical concepts. Here, there is a function of one reasoning process as mentioned, but the process does not take and rearrange the concept, but only activates the existing one, then connects it to form a general sequence and composition, and that conceptualizes the process of coordinating those relationships, which changes what the concept and the work they do (Clancey, 2001). Furthermore, regarding conceptualization, Oberle et al. (2004) define it as the idea of ontology in the context of formal explicit specifications. Or, the design of a process to produce a concept that is timeless and handles all that is needed so that it is a method applied to view events (Glaser, 2002; Nagle et al., 2013). Furthermore, although there is a process that is not simple, conceptualization is a simplified abstract view of a representation for a purpose (Oberle et al., 2004). So, conceptualization is a structured, mental prescribing process and refers to a series of procedures for developing a conceptual representation.

\subsection{The dimension of Cognitive Process and Knowledge}

With the conditions of the conceptual problem definition according to Rittle-Johnson and Schneider (2015), then in the process of completion, there are cognitive and metacognitive roles so that both contribute to the development of conceptual schemes (Iskandar, 2016). The role said by Kilpatrick et al. (2001) related to strategic competence and adaptive reasoning. While creative reasoning is related to conceptual knowledge as a network where links separate pieces of information (Bartholomew \& Strimel, 2018; Hendriana et al., 2018). Furthermore, in Iskandar's literature (2016) it has been said that metacognitive plays a role in connecting between conceptual understanding and procedural experience. At that time, several processes occur such as analyzing the complexity of the problem, selecting important information used, and thinking about the thought process during problem-solving. These skills are in the context of monitoring self-understanding and problem-solving activities so that it is no different from adaptive expertise in cognitive studies by Kilpatrick et al. (2001). Up to this point, there are some different terms but there 
is a similarity of words used. Such as knowledge or conceptual understanding, and indeed these two terms describe different contexts based on a point of view in solving problems so that both need to be further detailed according to each dimension.

Furthermore, so that students are proficient in mathematics and solve problems, actually in Kilpatrick et al. (2001) and Hendriana et al. (2018) indeed it has been mentioned that there are 5 independent strands and represent different aspects of the complex whole, two of which have already been mentioned, strategic competencies and adaptive reasoning, while the other three are conceptual understanding, fluency of procedures, and productive dispositions. However, Rittle-Johnson and Schneider (2015), and Sahin et al. (2015) say that mathematical competence rests on the development of two knowledge, conceptual and procedural. However, without conceptual knowledge, procedural knowledge is of limited value and can be so limited that the consequences must be based on understanding concepts (Österman \& Bråting, 2019; Radmehr \& Drake, 2017, 2018; Sahin et al., 2015). That is because organizational knowledge plays an important role in facilitating the use of knowledge (Alghadari \& Kusuma, 2018). Meanwhile, on the other hand, there have been difficulties to study the relationship between conceptual and procedural knowledge because test items or problems predominantly measure one type of two knowledge (Rittle-Johnson $\&$ Schneider, 2015). So from that open-ended problem is played to see the interaction of the two knowledge, because problems with these criteria can invite students' thinking processes that are different in ways or approaches to problem-solving (Bartholomew \& Strimel, 2018).

The importance of this two differentiated knowledge is to understand the interaction between the two, and in the research study that it is fundamental because it is a source of information about the construction or reconstruction of knowledge (Rittle-Johnson \& Schneider, 2015). The intended interaction is about how students represent and connect pieces of knowledge so that the organization increases retention, improves fluency, and facilitates learning related material, which is a key factor whether they will understand it indepth and can use it in problem-solving (Kilpatrick et al., 2001). The illustration above has led to the literature on Radmehr \& Drake $(2017,2018)$ regarding Bloom's revised taxonomy with a two-dimensional framework and has separated the dimensions of cognitive processes and knowledge. Furthermore, the use of one or more frameworks can help understand the processes and phenomena observed when exploring mathematical concepts, and Bloom's potential taxonomy is the largest, detailed, comprehensive, and flexible to explore a student's assessment of mathematical content.

\subsection{Knowledge in Function and Geometry to Solve}

In mathematics, there are concepts of function and geometry. The two concepts are studied along the journey of students' education which is adjusted to their level and ability to think. The higher level of education causes the learning of the two concepts will increasingly show and utilize the relationship between them. Such as in high school, which involves the concept of function and geometry is in the material sequence numbers or calculus. Here, we focus only on both of them, because calculus is included in the Indonesian mathematics education curriculum in high school and the conceptual problems that have been designed also for the material. The basic concept of calculus has used functions and geometry so that the level to study it is no longer recommended at the stage of concrete thinking. In the Borji et al. (2018) it has been said that some of the special difficulties students were the graphical representations of derivatives, those were about the basic concepts of calculus. Regarding that, Wagner and Sharp (2017), and Sahin et al. (2015) said, calculus had a reputation as a concept with terms of procedures that caused students to be trapped in trying to memorize algorithms and rules that did not involve the development of 
related conceptual knowledge. Strong conceptual knowledge serves to accelerate skills and procedures in calling information to solve problems (Setyawan et al., 2017). Therefore, the cognitive process for solving problems will involve all related potentials, so that conceptual and procedural knowledge that is no longer seen as two separate things, but combined in the complexity of abstract thinking processes.

Regarding mathematical concepts involving geometry, in van Hiele's theory, it has also been mentioned in Usman (2017) that there is a level of abstraction in which objects think of properties of a particular form intended to produce relationships between properties of that form. This becomes a reference that the process of thinking abstraction also exists for geometry even though it is not identical with concrete visualization. the theory is not for the framework of this study, but Wagner and Sharp (2017) have stated that it will be relevant if the conceptual problem is geometric. Visual representation of a geometric shape is a clue to a pattern or characteristic that contains a concept, resulting in successful problem-solving will depend on the ability of the individual to identify how the components exist and complement each other (Usman, 2017). Unlike the concept of function, because Kop et al. (2015) suggest that it cannot be accessed directly as a physical object but access to mathematical concepts can be obtained through representation.

This study presents a mathematical conceptual problem of students that determine the graph of derivative functions, but the knowledge given as a source of information was showing the geometry of a function only, without the details for an algebraic function. Therefore, some knowledge will be involved such as algebraic formulas, function domains, and meaningful relationships between representations (Kop et al., 2015). Choi and Hong (2014) mention the ability to read the information provided only in graphical form requires thinking about the nature of complexity. According to the results of the study Tokgoz and Gualpa (2015), there is a tendency for students to solve problems with these characteristics by determining the algebraic representation. The problem is the concept of calculus which combines with the concepts of function and geometric shape, therefore we define it as a geometric-function problem. Furthermore, Tobin (2012) stated that a problem was seen as a geometry problem when the geometry elements of the curve can be communicated with the concept of negative or positive gradients at a certain point so that the problem was solved without involving an algebraic function formula.

\subsection{The Present Study}

From previous studies, Borji et al. (2018) reported that most students had problems developing mental constructs to calculate derivatives so they did not pay attention to the relationship between functions and their derivatives in an interval. The report has become a point of view for conducting relevant studies. Kop et al. (2015) in his study of composing effective and efficient strategies for making graphs without the help of graphical tools, has shown that two-dimensional frameworks, recognition, and heuristics, can be used to describe graph formulation strategies. However, the dimensions of the study are different from this study. The dimensions of this study are cognitive processes and knowledge. The dimensions of cognitive processes are distinguished by the dimension of knowledge so that the details of the analysis with this framework approach are more comprehensive than just one dimension. Radmehr and Drake (2018) have made these differences based on the use of verbs for cognitive processes and nouns to show knowledge. Furthermore, procedural knowledge refers to the use of symbols from a system of rules or procedures for solving mathematical problems, while conceptual knowledge is the knowledge that is rich in conceptual relationships (Österman \& Bråting, 2019; Radmehr \& Drake, 2017, 2018). The quotations above become the theory in this study to analyze the process of solving geometric 
problems in student functions based on the dimensions of cognitive processes and their knowledge.

\section{METHOD}

\subsection{Student's Participant}

Explorative studies with this simple technique of constant comparative were initially carried out purposively to seven students of class XI in the 2017/2018 school year in a science program at one of the secondary schools in the West Jakarta area. The selection of them aims at the needs of this study, which shows the conceptualization process so that the students involved are those who have the potential to solve the problem. Therefore, these students are recommendations from their mathematics subject teachers. Then, all of them solved the geometry-function problem that we provided. In addition to solving problems with paper and ink, students also interpret what they write on the same sheet of paper so that it shows their flow of thinking in progress.

\subsection{Data Collection}

This study involves problems related to function and geometry in calculus. Of the seven students who have solved geometric-function problems, the results of the solutions are obtained along with their interpretations of what they have made. The problem they solved was adapted from Tobin (2012), was to determine the sketch of the graph model of the derivative function of each graph in Figure 1.

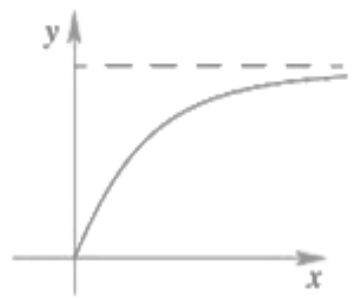

(a)

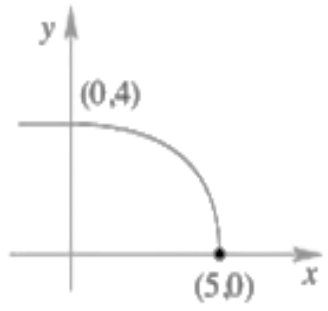

(b)

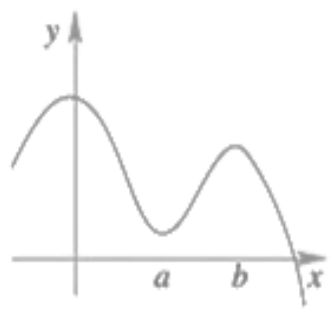

(c)

Figure 1. Sketch of the function graph

Figure 1 contains three different problems, (a), (b), and (c). Henceforth, sometimes we say Figure 1 (a) as a problem 1 (a), and so for others. The three problems were solved by the students. We encourage them to complete sequentially, but not oblige because conceptual ideas of completion are purely the result of their thoughts written. Each student's paper that reads is the primary data to be analyzed. Each student will be sampled if they show a solution accompanied by the interpretation they describe in writing.

\subsection{Data Analysis}

Not all results of student completion become part of data analysis because not all of the analysis objects provide completeness as needed. After being examined from collected data, there were only three of the seven students selected to be the sample analysis in this study, and each of them was marked with the initials of their names, AN, NI, and PR. From solving problems, there are several foci analyzes that become our point of view, namely mathematical concepts used for completion, cognitive processes involved and metacognitive functions that control, as well as conceptual and procedural knowledge that operates. The 
analysis refers to the Radmehr \& Drake $(2017,2018)$ literature on the revised Bloom taxonomy to compile a generalization of the conceptualization process for solving geometryfunction problems.

\section{RESULTS AND DISCUSSION}

\subsection{Results}

It has been stated that there is a factor of subjectivity based on his knowledge which directs students to choose a particular way of solving a problem. Therefore, in this study that of the three students. there was no one answer that is the same as the others, but the basis of the process of conceptualizing the solution is that it tends to be the same, for example for problem 1(b). There is a conceptualization process by a student who is completely different from the other two students, for problem 1(c) shown by PR, while for problem 1(a) is indicated by NI. It is clear that when different conceptualization processes will find different solutions. This is following the problem category as an open-ended type. Although, the three students have answered the problem, each of them has missed a basic relevant mathematical concept to conceptualize the solution they made, namely the domain and range of functions. For more information about students' responses to problems, here are each of their completion processes.

\subsubsection{AN's Solving Process}

The focus in Figure 1 (a), AN recalling his knowledge of functions and graphs. Because it recognizes graphs, AN sets $e^{x}$ as the most common classification for that. However, the graph of the exponent function did not mean the same as the image so there is another process to equalize the form, and that is called the "reversed" process. The process as an application of the concept of reflection in geometric transformation, although the detailed application of the concept was not written thoroughly, it was written that the formula of the function of the transformation results is $y=-e^{-x}$. Up to this point, AN has not finished using the concept of transformation, then it was intended to make a curve until it was similar to the model image 1 (a), with translation $\left[\begin{array}{ll}0 & 1\end{array}\right]$ so that it passes through the base of the coordinates, and defines the graph asymptote with $\lim _{x \rightarrow \infty}-e^{-x}+1=1$. By its exemplifying process, there is no elemental detail in the problem that shows information about the asymptote boundary, so AN represented the graph in Figure 1 (a) in the algebraic function formula $y=-e^{-x}+a$, for a real number element. The algebraic formula after being derived was $y^{\prime}=e^{-x}$ and sketched as shown 2(a). The graph model of the derived function that has been drawn by $\mathrm{AN}$ is as follows.

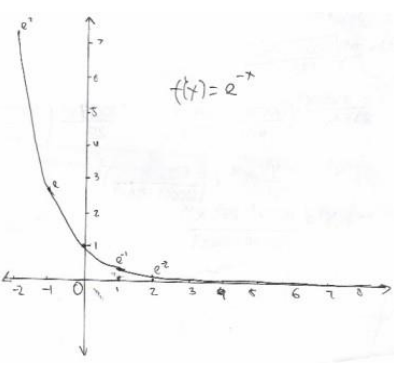

(a)

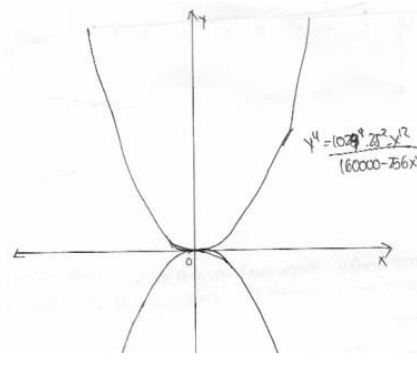

(b)

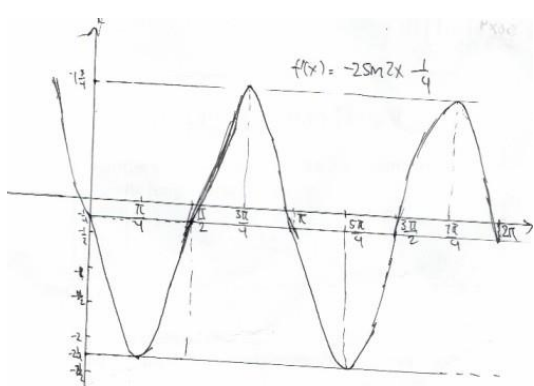

(c)

Figure 2. The completion problem by AN 
Figure 2 was a problem-solving by AN of the three graphical forms in Figure 1. Figure 2 (a) is a problem-solving for Figure 1 (a), also the letters are adjusted for the other two. Following is a description of the process for solving problem 1 (b). An outline of the substance of the conceptual idea of problem-solving was no different. In other words, the first step in the process of solving problem 1 (a) was not an exception so that it affected the settlement activity for the next two numbers. However, because there was an element of graphical representation that was loaded problem 1 (b) so with its conceptual knowledge on coordinates $(0,4)$ and $(5,0)$, then AN concluded that it was an ellipse. The pair of coordinates in the graph and the terminology of the forms already exist in the AN knowledge dimension, so that the recalling process was carried out in the cognitive dimension. In further information, the results of checking and differentiating among the coordinate axes in the graphic image, so AN considers that the graphic form was more "rectangular", and if the more square the higher the degree of power of the ellipse equation. Finally, AN produced the algebraic formula for the graph.

$$
\frac{x^{4}}{625}+\frac{y^{4}}{256}=1
$$

Based on the implicit algebraic equation above, AN implemented an explicit function and then used implicit differentiation, so that the derivative results obtained from the formula is as follows:

$$
f^{\prime}(x)=y^{4}=\frac{1024^{4} \times 25^{2} \times x^{12}}{160000-256 x^{4}}
$$

For the above function formula, AN illustrated the graph of the derived function for Figure 1 (b) as shown in Figure 2 (b), so the problem is solved. Furthermore, for the series of problem-solving processes 1 (c), several conceptions had been interpreted by AN in the answer paper. Such as, graphs that started from $(0, a)$ then up and down so that it loaded functions $\cos x$, but the model was getting down so it also loaded $-x$, then, the coefficients had begun to be adjusted resulting in the shape of the function approaching the Figure 1(c). The process for solving this problem, AN did not write many details, but AN produced algebraic formulas in explicit function as follows.

$$
y=2+\cos 2 x-\frac{x}{4} \text { dan } y^{\prime}=-2 \sin 2 x-\frac{1}{4}
$$

The derivative of $\mathrm{y}$ for $\mathrm{x}$ was $\mathrm{y}$ '. The function $\mathrm{y}$ was an algebraic form of graphic Figure 1(c). Whereas function y was an algebraic form for Figure 2 (c) representation. The concepts were solved by AN, on the three problems illustrated the similarity of processes.

\subsubsection{NI's Solving Process}

All students in solving problems will certainly be recalling their relevant knowledge. NI had also done it to solve these three graph problems. He wasn't different from the previous subject because the solution was conceptualized by determining the algebraic formula from the graph in Figure 1, but there was something different from the algebraic formula, through his conceptual knowledge, NI had conceptualized that the classification for Figure 1(a) led to the form $y=-x^{-1}$. However, factual knowledge assumed that the graph of the algebraic formula did not match the picture on the problem, and its least upper bound equally zero for real positive number function domain, then NI with its metacognitive knowledge made adjustments by adding a as an implementation of the translation concept so that it became the upper or minimum limit. Here, we found that the algebraic formula was 
constructed by NI produced an explicit form $y=-x^{-1}+a$ and $a$ a real number, but the answer was less precise, because $a$ was not defined in detail as a positive real number, and the graph of the function also did not pass through the origin, it would have an impact on the representation for the derived function.

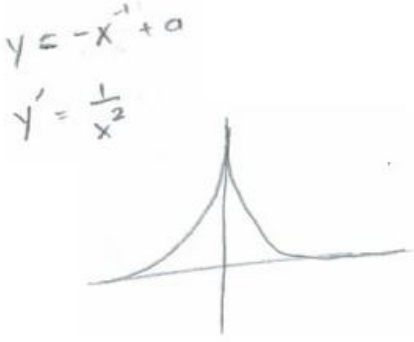

(a)

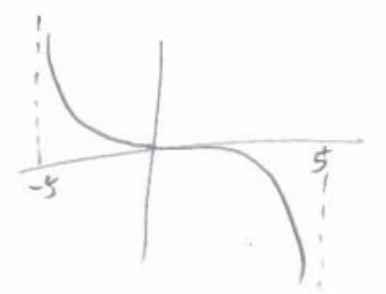

(b)

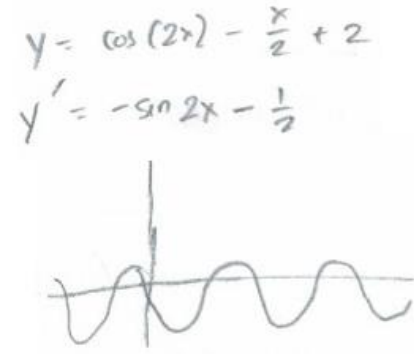

(c)

Figure 3. Problem Answers by NI

However, through the algebraic formula, the derivative functions and graphs, $y^{\prime}=1 / x^{2}$ immediately known and illustrated by NI, as shown in Figure 3 (a), so that $a$ did not become a problem that arose due to the derivative function of $x$. The following are three pictures from the graph of the derivative function as a result of the conceptualization problem-solving that had been constructed by NI. Figure 3 is the three graphic images that NI had been made for each number of problems presented. Each graph was drawn from the function constructed, then differentiable and represented by a sketch in the coordinate plane. The following is part of the description for the construction of functions so that Figure 3 (b) is obtained. With his factual knowledge, NI stated that Figure 1 (b) as an arc that intersects the $\mathrm{x}$-axis was more curved than an arc that intersects the $\mathrm{y}$-axis, so there was a difference in rank for the variables $x$ and $y$. The more curved arc was interpreted as a variable of rank 2 while the others of the rank of 4 , and NI produced the following equation accompanied by the equation for its derivative.

$$
\left(\frac{x}{5}\right)^{4}+\left(\frac{y}{4}\right)^{2}=1 \text { and } y^{\prime}=-8\left(1-\left(\frac{x}{5}\right)^{4}\right)^{-\frac{1}{2}}\left(\frac{x}{5}\right)^{3}
$$

Based on the two algebraic representations above, the explicit form y' was derived from another representation. Here it had indirectly seen that it was obtained from an initial algebraic representation (in the implicit form), which was first converted to an explicit form involving procedural and conceptual knowledge. Derived algebraic functions were obtained and images made in the coordinate plane so that the result was Figure 3 (b). In the figure, NI had been attributed to the domain for the representation of the derived result that the interval was $-5<x<5$. However, we did not agree to the geometric shape of Figure 3(b) at intervals $-5<x<0$ because the concept of the domain that the function had been implemented, was not in accordance that's showed in Figure 1 (b), and it was clear that at that interval, it should not be a function descending from the problem, but rather a zero equal gradient. Thus the process of solving problem 1(b) had worked on by NI, continued with problem 1 (c). The first impression after seeing the problem Figure 1(c) that had been made by NI was about trigonometric functions. This was the conception that the waves were classified as such $\cos 2 x$, and there are coefficients along with variables that were $-x / a$ outside of its trigonometry due to a declining graphical model. Then, he did not write down many other 
interpretations, thus describing his procedural knowledge so that the resulting algebraic formula of the problem and its derivative functions is as follows:

$$
y=\cos (2 x)-\frac{x}{2}+2 \text { dan } y^{\prime}=-\sin (2 x)-\frac{1}{2}
$$

The formula above is the algebraic function formula $y^{\prime} . y^{\prime}$ is the derivative of $y$ for $x$. The two algebraic formulas are representations for each corresponding graph. The function formula y is for Figure 1(c) and y' is for image 3 (c). At this point, the completion model of two students has been the result of this study and as material for comparative analysis. The explanation above, along with all the NI's descriptions were the process of problem-solving which conceptualized in constructing the function formula.

\subsubsection{PR's Solving Process}

There has been a different recalling mathematical concept that was done by PR because the two others used the trigonometry concept. It was polynomial, maximum, and inflection points for solving 1(c)'s problem. Before describing it, it would begin with the process of problem solving 1(a). Involving conceptual and procedural knowledge, there were several processes of exploration of the functions to obtain appropriate images. For example for problem 1(a) with the exponent function $y=a^{x}$, exemplify $a$ is equal to 2 and it turned out it was not by the shape of the graph so, PR reflected it on the $x$-axis to be $y=-2^{x}$. Reflection continued on the $y$-axis, but in the end, he wrote $y=-2^{-\sqrt{x}}$, and to fit the picture on the given problem, with the concept of translation, he added its function with 1 , it became $y=1-2^{-\sqrt{x}}$. From the findings of the algebraic formula, the PR then generalized it with the number $e$. Following successive representations for the functions and their derivatives that he described were $y=1-e^{-\sqrt{x}} y^{\prime}=\sqrt{x} / 2 x e^{\sqrt{x}}$ and for 1 (a). Figure 4 is a graph of the derivative function for each of the graphs in Figure 1.

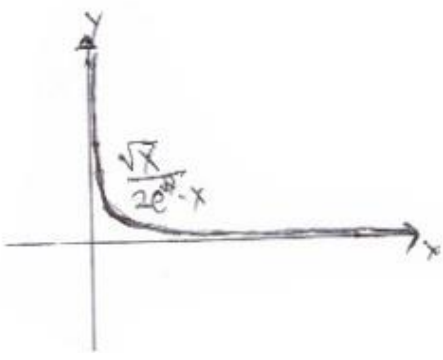

(a)

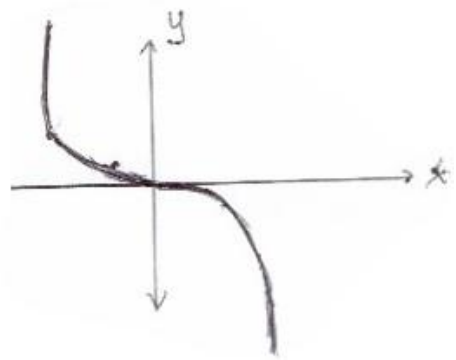

(b)

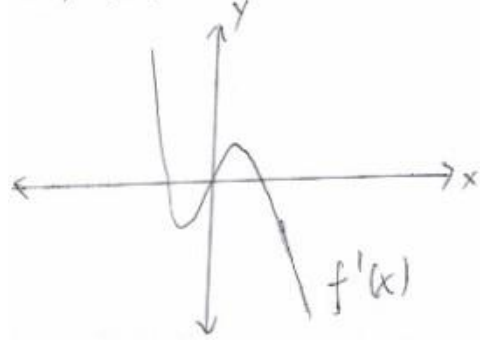

(c)

Figure 4. Problem Answers by PR

Figure 4 contains three parts, namely (a), (b), and (c). PR describes Figure 4 (a), Figure 4 (b), and Figure 4 (c) respectively for the derivative functions of problems 1(a), 1(b), and 1(c). The completion process 1(a) has been described, and now is for the process of problem 1(b). For this problem, PR determines the initial form as follows:

$$
\frac{x^{4}}{a^{4}}+\frac{y^{4}}{b^{4}}=1
$$

PR did not provide many detailed interpretations, but we assumed that his works were related to factual and conceptual knowledge about the concept of circles and graphical shapes. Where $a$ is the intersection point of the graph on the $x$-axis, and $b$ is the intersection 
point with the y-axis, so that by substituting the values of $a$ and $b$, we got an implicit form of algebraic representation for the graph model. Furthermore, using the algebraic representation, PR also procedurally determined the representation for derivatives, and was written as below:

$$
y^{\prime}=-\frac{625 x^{3}}{8 \sqrt{160000-625 x^{4}}}
$$

Based on the picture above, $y^{\prime}$ is an algebraic representation of the function derivative in the graph model in Figure 4 (b). PR described the graph of the derived function as the end of the settlement activity for problem 1(b). Proceed with the settlement process for problem 1 (c) as a supplement for comparative materials for other solutions. PR's knowledge of the problem, made him conceptualize that the function of the graph was a polynomial with the degree of four because there was a turning point and three stationary points, $x=0 x=a x=b$ and. Through these concepts, PR created a functional formula as follows:

$$
f^{\prime}(x)=-(x-a)(x-b) x=-x^{3}+(a+b) x^{2}+a b x
$$

The formula above is two algebraic representation models for the same curve. It was written in PR's work paper. PR constructed these representations, where the similarity of the two models was a symbol of his skills in the context of procedural knowledge.

\subsection{Discussion}

\subsubsection{Student Perspective in Solving Process}

The completion process, which was done by PR, had complimented our assumptions about the settlement concept of two of his friends who started. Based on the completion process that has been described above, the three students had viewed that the problem is about constructing algebraic function formulas and had shown a series of cognitive processes that were not simple to the bridge of the solutions. Therefore, the cognitive processes that operate and the knowledge applied by the three students to solve the problem, focus on the conceptualization of algebraic representations, to determine the derivative of functions and draw graphics. It could be said, they were not an intellectual challenge for them, and it had been shown by all three. This finding displays the same conditions as in the quote Tokgoz and Gualpa (2015) that students tend to find algebraic formulas from a function graph, as a bridge sketches a graph of its derivative functions. In quotations from several studies, it is stated that constructing a derivative function graph is to identify the gradient value along the curve, where the gradient value is relatively positive or negative, and increase or decrease (Borji et al., 2018; Hong \& Thomas, 2015; Tobin, 2012), but the case here was identifying a graphical model from the algebraic function formula.

As a result, the findings of this study are different from the discussion of Tobin (2012), the problem is seen as a geometry problem where the geometrical elements of the curve are communicated with negative or positive gradient concepts at a certain point to produce the differential function graph. Thus, generally, there are at least three processes of conceptual representation, in this case, that is constructing algebraic function formulas, determining derivative functions, and sketching graphs. The three processes in question are one example of a procedure but not an algorithmic or symbolic procedure (Alghadari \& Kusuma, 2018), which was developed through problem-solving (Rittle-Johnson \& Schneider, 2015). 
Thus, for the findings in this study that the problem of students was a matter of representation of algebraic functions. In Setyawan et al. (2017), and Hong and Thomas (2015), an item was said to be a matter of function if the concept can be seen in the representation of images and symbols. While in Nagle et al. (2013) said that the mathematical concept related to the gradient of functions was reported that it presents challenges for students. So, it is fixed as the problem for students. However, what made students so conceptualized that it was a matter of function. Setyawan et al. (2017) and Dossey (2017) stated that students use a representation of a mathematical topic because it is significant to their conceptual knowledge, and the representation chosen at completion is the result of a decision of a phenomenon that has become its experience. Then, it has been mentioned in the literature of Setyawan et al. (2017) that conditions from the point of view as individual preferences based on information obtained because the perspective of an object is related to the appearance of the shape or size received by the senses. Meanwhile according to Borji et al. (2018), that it is because students are too late to realize the relationship between derivative functions and their main functions due to lack of respect for the relationship between the two in the graphical representation of the learning process. Whereas translating between representations is a powerful communication tool for mathematical thinking (Setyawan et al., 2017). In this case, we use the word main function to refer to the function before it is differentiable. Then, Choi and Hong (2014) states that students' perspectives are inclinations that depend on algebraic thinking styles rather than geometric thinking styles.

However, there were consequences for problems that were resolved through the process, students transform the graph so that it was represented in algebraic formulas. Therefore, the process required the ability to read expressions and make rough estimates of the patterns that emerge in representations (Kop et al., 2015). This was one reason why the process takes longer. Exploration for a suitable graphical model has been demonstrated by all three students. It was also found in this study that the three students had skipped about the concept of the domain of function on the results of the derivative graph construction. We agree with the statement of Borji et al. (2018) based on the findings of this study that students do not pay attention to the relationship between functions and their derivatives in one interval. This finding fits the statement of Hong and Thomas (2015) that using algebraic thinking performs poorly in exams. Students usually show difficulty in using the function property (Kop et al., 2015; Tokgoz \& Gualpa, 2015), there was a factor that is less flexible in thinking about the concept of function where it is needed in mathematics and problemsolving (Hong \& Thomas, 2015; Kop et al., 2015) because it includes complex properties to think about when reading information provided only in graphic (Choi \& Hong, 2014). It can be stated that perhaps the students' differential learning process places more emphasis on algebraic representations, so they will neglect a little graphical representation (Borji et al., 2018), causing students to depend on these performance processes (Hong \& Thomas, 2015), consequently, they are skilled in algebraic algorithm but difficulty in understanding concepts (Choi \& Hong, 2014).

\subsubsection{Concept-Image in Conceptualizing}

With the findings of this study, the nature and criteria of the conceptual problem are indeed open-ended because there are conceptual constraints that students encounter thus inviting students to construct different processes and solutions. Conceptual geometricfunction problems in this study are calculus problems related to functions and gradients. There are several functional concepts for deep understanding, such as domains and codes (Setyawan et al., 2017), and that requires knowledge of boundaries, derivatives, asymptotes, properties, and intervals (Hong \& Thomas, 2015; Tokgoz \& Gualpa, 2015), as well as 
increase and decrease intervals, extreme values are elements and functional properties represented graphically (Kop et al., 2015). However, the conceptualization process for problem-solving, and has been explained above, as stated (Widodo et al., 2019), that it cannot be separated from students' viewpoints on problems, or how students perceive problems to be solved, but still relies on conceptual knowledge as well. Nagle et al. (2013) have mentioned that learning calculus does require significant mathematical understanding to form a complete and connected concept image. Therefore, knowledge and understanding of mathematical concepts is a capital that also supports the completion process to conceptualize the algebraic function formula. Here, the three students explore the algebraic formulas of their functions and geometric shapes, until they are found to fit the model with the graph figure. The three completion processes of each student all illustrate a graph model of different derivative functions. This is because concepts are operated at different stages, or the choice of concepts for the construction of representations is also different. Accordingly, Dossey (2017) has said that students think differently because of some mathematical concepts applied. The difference is the acquisition of each individual's concept image as a total cognitive structure related to the concept (Nagle et al., 2013), and student representation of a concept is influenced by the level of student development in forming mental models (Setyawan et al., 2017).

Solving problems with the conceptualization process, as shown by the three students, which also involves covariational reasoning even though with a rough pattern, namely connecting between two variables, there is a graphical model that cannot be declared wrong for a certain interval. However, it is said in Sahin et al. (2015) that although students are able and correct to solve derivative problems by implying procedural understanding, they do not understand the meaning of the concept of derivatives conceptually. Furthermore, it is a result of the deficiency of conceptual understanding of important concepts in mathematics from the relationship between the concept and the underlying relationship so that students fill it with procedural and computational understanding as essential with little conceptual understanding. The results of this study are no different from the study report Nagle et al. (2013) about concept images and internal conceptual systems of students who are still fragmented.

\subsubsection{Toward Cognitive Process and Knowledge}

One of the findings of this study is that students explore more examples of algebraic's expressions, it was a sign that students' procedural knowledge is more dominant and they believe in implementing it. Students' confidence in their knowledge, because they are more familiar with the ideas that underlie the method of solving (Hong \& Thomas, 2015). Rightly stated Sahin et al. (2015), and Wagner and Sharp (2017), and with this finding, it is still intended that calculus reputation is implied by students memorizing algorithms and rules. These cases were no different from the findings of Sahin et al. (2015) which states that none of the respondents experienced difficulties in connecting mathematical concepts embedded in graphical models and exploration activities in models, even though the understanding was not relational, or was rather instrumental. Furthermore, this has to do with the role of memorizing algorithms in learning derivatives so that it ignores important mathematical basic concepts, and graphs of derived functions rarely become visual objects that directly refer to the derivative function. Then when referring to student learning textbooks, the interpretation of the geometry of the derivative function is the result of a sketch of the algebraic representation and rarely the reverse. Therefore, related to these conditions, Sahin et al. (2015) suggested that it might be better to emphasize derivatives as a function and 
construct its graph through associating the slopes of different tangent lines of the curve representing the different slopes.

Glaser (2002) has mentioned that researchers may not be able to handle the conceptualization boredom with constant comparisons while coding, gathering with theoretical sampling and analyzing, writing theoretical memos and saturating concepts. However, studies of the conceptualization process of solving geometric-function problems have shown that the three responses of students describe their performance in the context that they depend procedurally and involve little covariational reasoning. While Sahin et al. (2015) have mentioned that such conditions imply knowledge without understanding the basic meaning of the concept and how it is interrelated in the context of derivatives. Furthermore, another important finding in this study is that students are not yet aware of the relationship between the function and it's derivative graphically without having to involve the construction of algebraic formula functions. In other words, they cannot connect between the graph of functions and the negative or positive of the gradient of a function at certain intervals. It is the basic concept of calculus about the relationship between the gradient of the tangent line at the point on the curve and the slopes of the secant lines. Although in this study that students can reason about the role of concepts involved in the problem-solving process, but in Sahin et al. (2015) mentioned that the relational understanding of derivatives must include all the underlying big ideas. This finding is appropriate as in the literature of Borji et al. (2018) about the basic concepts of calculus which are of particular difficulty for students in the graphical representation of derivatives, and are the same as the report in the study of Sahin et al. (2015) that students tend to have difficulty in understanding the basic concepts of calculus. From the results of this study to emphasize student learning in the next concept section adapted to the conceptualization that is most prevalent to mediate students in a didactic atmosphere from a strong knowledge base to build more advanced derivative function conceptualizations. This is important because it is part of the investigation suggestions for the concept image developed by students regarding how they understand and relate concepts (Sahin et al., 2015), and school academic culture (Nagle et al., 2013).

\section{CONCLUSION}

Through solving conceptual geometric-function problems, students are required to recall their knowledge to be processed in cognitive space. Such knowledge is from the point of view that students have seen it as a problem of algebraic function representation, and they have shown at least three processes of conceptual representation in this study, that are constructing algebraic function formulas, determining function derivatives, and sketching graphs. However, this conceptualization process has consequences, that is, students transform the graph so that it is represented in algebraic formulas, and that has resulted in the concept of the domain of function being overlooked. In the process, students explore the algebraic formulas of their functions and geometric shapes until they are found to fit the model with the graph figure. Here, there is no similar construction process because mathematical concepts are operated at different stages, and the difference is the acquisition of each individual's concept image as the total cognitive structure associated with the concept which is influenced by the level of student development in forming mental models. In this case, some students are able and correct to solve the problem, but the work implies procedural understanding which does not understand the meaning of the concept of derivatives conceptually. This is a result of the lack of understanding of the concept of the relationship between the concept and the underlying relationship so that the internal conceptual system is still fragmented. This is a sign that students' procedural knowledge is 
more dominant and they believe in implementing it, not yet aware of the relationship between the function and it's derivative graphically, and this relates to the role of memorizing algorithms so that it ignores important mathematical basic concepts.

This is a special part of the conceptualization process in problem-solving activities, namely precisely regarding the involvement of the relationship between functions and their geometric shapes. The process serves to emphasize student learning to construct conceptualizations of more advanced derivative functions that are adapted to the conceptualization that is most prevalent due to factors of school academic culture. Therefore, further studies must be carried out for broader purposes.

\section{REFERENCES}

Alghadari, F., \& Kusuma, A. P. (2018). Pendekatan analogi untuk memahami konsep dan definisi dari pemecahan masalah. In Prosiding Seminar Nasional Matematika dan Pendidikan Matematika (SNMPM), Cirebon.

Alghadari, F., Yuni, Y., \& Wulandari, A. (2019). Conceptualization in solving a geometricfunction problem: an effective and efficient process. Journal of Physics: Conference Series, 1315(1), 012004. https://doi.org/10.1088/1742-6596/1315/1/012004

Bartholomew, S. R., \& Strimel, G. J. (2018). Factors influencing student success on openended design problems. International Journal of Technology and Design Education, 28(3), 753-770. https://doi.org/10.1007/s10798-017-9415-2

Borji, V., Font, V., Alamolhodaei, H., \& Sánchez, A. (2018). Application of the complementarities of two theories, APOS and OSA, for the analysis of the university students' understanding on the graph of the function and its derivative. Eurasia Journal of Mathematics, Science and Technology Education, 14(6), 2301-2315. https://doi.org/10.29333/ejmste/89514

Choi, Y. J., \& Hong, J. K. (2014). On the students' thinking of the properties of derivatives. The Mathematical Education, 53(1), 25-40. https://doi.org/10.7468/mathedu.2014.53.1.25

Clancey, W. (2001). Is abstraction a kind of idea or how conceptualization works? Cognitive Science Quarterly, 1(3-4), 389-421.

Dossey, J. A. (2017). Problem solving from a mathematical standpoint. In B. Csapó \& J. Funke (Eds.), The Nature of Problem Solving: Using Research to Inspire 21st Century Learning (pp. 59-72). OECD Publishing. https://doi.org/10.1787/9789264273955-6-en

Glaser, B. G. (2002). Conceptualization: On theory and theorizing using grounded theory. International journal of qualitative methods, 1(2), 23-38. https://doi.org/10.1177/160940690200100203

Hendriana, H., \& Fadhillah, F. M. (2019). The students' mathematical creative thinking ability of junior high school through problem-solving approach. Infinity Journal, 8(1), 11-20. https://doi.org/10.22460/infinity.v8i1.p11-20

Hendriana, H., Prahmana, R. C. I., \& Hidayat, W. (2018). Students' performance skills in creative mathematical reasoning. Infinity Journal, $7(2)$, 83-96. https://doi.org/10.22460/infinity.v7i2.p83-96 
Hong, Y. Y., \& Thomas, M. O. (2015). Graphical construction of a local perspective on differentiation and integration. Mathematics Education Research Journal, 27(2), 183-200. https://doi.org/10.1007/s13394-014-0135-6

Iskandar, S. M. (2016). Pendekatan keterampilan metakognitif dalam pembelajaran sains di kelas [Approach of metacognitive skills in science learning in the classroom]. Erudio Journal of Educational Innovation, 2(2), 13-20.

Kilpatrick, J., Swafford, J., \& Findell, B. (2001). Adding it up: Helping children learn mathematics. The National Academies Press.

Kop, P. M., Janssen, F. J., Drijvers, P. H., Veenman, M. V., \& van Driel, J. H. (2015). Identifying a framework for graphing formulas from expert strategies. The Journal of Mathematical Behavior, 121-134. https://doi.org/10.1016/j.jmathb.2015.06.002

Mumu, J., Prahmana, R. C. I., \& Tanujaya, B. (2017). Construction and reconstruction concept in mathematics instruction. Journal of Physics: Conference Series, 943(1), 012011. https://doi.org/10.1088/1742-6596/943/1/012011

Nagle, C., Moore-Russo, D., Viglietti, J., \& Martin, K. (2013). Calculus students' and instructors'conceptualizations of slope: A comparison across academic levels. International Journal of Science and Mathematics Education, 11(6), 1491-1515. https://doi.org/10.1007/s10763-013-9411-2

Oberle, D., Volz, R., Staab, S., \& Motik, B. (2004). An extensible ontology software environment. In S. Staab \& R. Studer (Eds.), Handbook on ontologies (pp. 299-319). Springer. https://doi.org/10.1007/978-3-540-24750-0_15

Österman, T., \& Bråting, K. (2019). Dewey and mathematical practice: revisiting the distinction between procedural and conceptual knowledge. Journal of Curriculum Studies, 51(4), 457-470. https://doi.org/10.1080/00220272.2019.1594388

Polya, G. (1981). Mathematical Discovery on Understanding, Learning and Teaching Problem Solving, Volumes I and II. John Wiley \& Sons.

Radmehr, F., \& Drake, M. (2017). Revised Bloom's taxonomy and integral calculus: unpacking the knowledge dimension. International Journal of Mathematical Education in Science and Technology, 48(8), 1206-1224. https://doi.org/10.1080/0020739X.2017.1321796

Radmehr, F., \& Drake, M. (2018). An assessment-based model for exploring the solving of mathematical problems: Utilizing revised bloom's taxonomy and facets of metacognition. Studies in Educational Evaluation, 59, 41-51. https://doi.org/10.1016/j.stueduc.2018.02.004

Rittle-Johnson, B., \& Schneider, M. (2015). Developing conceptual and procedural knowledge of mathematics. In R. C. Kadosh \& A. Dowker (Eds.), Oxford handbook of numerical cognition (pp. 1118-1134). Oxford University Press.

Sahin, Z., Yenmez, A. A., \& Erbas, A. K. (2015). Relational understanding of the derivative concept through mathematical modeling: A case study. Eurasia Journal of Mathematics, Science and Technology Education, 11(1), 177-188. https://doi.org/10.12973/eurasia.2015.1149a 
Setyawan, F., Prahmana, R. C. I., Istiandaru, A., \& Hendroanto, A. (2017). Visualizer's representation in functions. Journal of Physics: Conference Series, 943(1), 012004. https://doi.org/10.1088/1742-6596/943/1/012004

Tobin, P. (2012). Mathematics Standard Level: For Use with the International Baccalaureate Diploma Programme (IB Mathematics) (F. Cirrito, Ed.). IBID Press.

Tokgoz, E., \& Gualpa, G. C. (2015). STEM majors' cognitive calculus ability to sketch a function graph. In 2015 ASEE Annual Conference \& Exposition, Seattle, Washington. https://doi.org/10.18260/p.24733

Usman, A. I. (2017). Geometric error analysis in applied calculus problem solving. European Journal of Science and Mathematics Education, 5(2), 119-133. https://doi.org/10.30935/scimath/9502

Wagner, J., \& Sharp, J. (2017). A calculus activity with foundations in geometric learning. The Mathematics Teacher, 110(8), 618-623. https://doi.org/10.5951/mathteacher.110.8.0618

Widodo, S. A., Nayazik, A., \& Prahmana, R. (2019). Formal student thinking in mathematical problem-solving. Journal of Physics: Conference Series, 1188(1), 012087. https://doi.org/10.1088/1742-6596/1188/1/012087 
